\title{
Comecon tackles the energy crisis
}

\section{Vera Rich explains how the Eastern bloc is coping with the rising price of oil}

Recent oil price rises throughout Eastern Europe, coupled with Romania's unprecedented demand that tourists from other Comecon countries must purchase their petrol for hard currency, at first glance accords ill with Mr Kosygin's remarks at the Comecon summit at the end of June. In fact there is no contradiction. What Mr Kosygin promised for the next Five Year Plan (1981-86) was a $20 \%$ increase in energy supplied by the Soviet Union to the bloc, not specifically oil.

Commenting on Kosygin's speech, a TASS reporter quoted Dmitrii Mendeleev, discoverer of the periodic table, that "to use oil or banknotes for heating comes to about the same thing"'. While the West has based its economy on oil, he continued, the Soviet Union has "harmoniously", developed all fuel and energy branches of the economy: coal, shale, hydroelectricity and nuclear power, as well as the oil and gas fields.

Kosygin's statement of existing Soviet energy supplies to the Comecon allies is impressive: during this Five Year Plan, some 370 million tonnes of oil, 46 million tonnes of oil products, 88 million cubic metres of gas and 64 million $\mathrm{kW}-\mathrm{h}$ of electricity. But the official communiques of the meeting stressed that from now on the extraction of oil and gas would continue to increase, but would be devoted primarily to the needs of the chemical industry. It seems likely that a major proportion of any increase in energy supplies from the Soviet Union will take the form of electricity. A massive plan to step up generating capacity in the USSR is already under way. From 1980, all increases in the European part of the USSR will be nuclear; east of the Urals, a network of thermal power stations will be brought into the grid, fired by lignite, of which there are abundant local supplies.

All Comecon countries, with the exception of the Soviet Union, are now net importers of petroleum. Even Romania, whose role as a former major oil producer is commemorated by an oil rig in the state coat of arms, has to import a certain proportion from the hard currency market. Although energy is one of the specific sectors selected for the "long-term targetorientated" Comecon integration programmes approved in 1976 (for the period 1975-1990), Soviet oil prices to the other Comecon countries are calculated from the average world price over the last five years and reassessed each year. Moreover, Soviet-exported oil accounts for only $80 \%$ of the other members' demands: the rest they must purchase on the world market.

Furthermore, the long-term availability of Soviet oil appears to be in some doubt. All official sources unequivocally

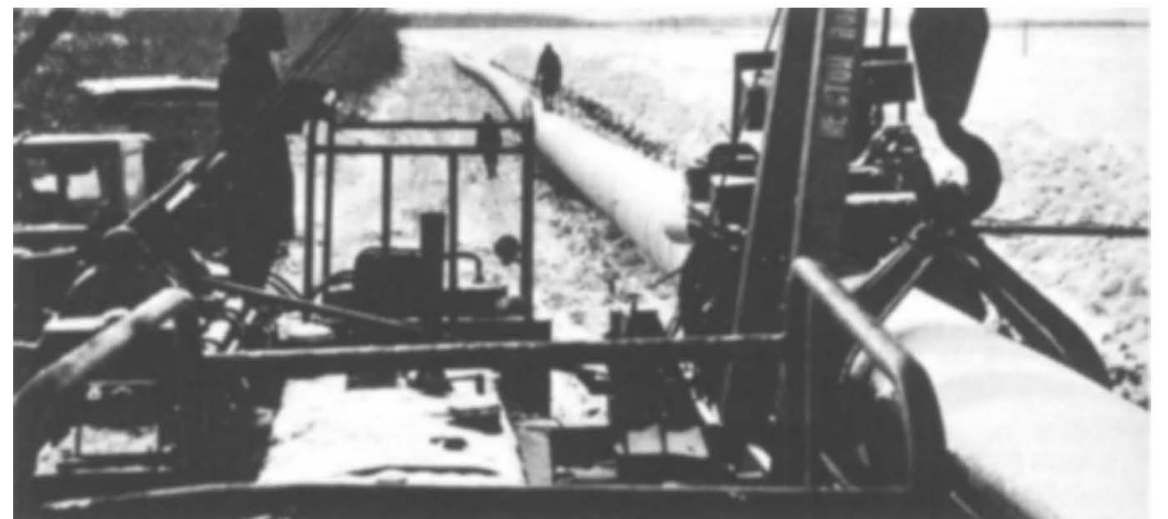

Russian pipeline: the oil will keep flowing, say Soviet officials

repudiate the CIA predictions of an impending Soviet oil crisis. Shortfalls are attributed to the technical difficulties of bringing the East Siberian fields onstream, and the consequent depletion of the West Siberian fields more rapidly than planned. Occasionally, too, "anti-social manifestations" among the oil workers may be blamed for a temporary deficit (Bakiskii Rabochii 1 June, 1979).

Nevertheless, nuclear power is seen as the mainstay of the future energy needs of the bloc, and the construction of nuclear power stations is a top priority in all member countries except Poland. Here the still abundant coal reserves make it possible to defer the introduction of nuclear power on a commercial scale, and the one nuclear power station so far scheduled (a joint venture with the Soviet Union) is seen, in the words of one energy expert, as "a pilot project for the Polish situation"

Socialist planning, it appears, leaves no room for an environmental lobby against nuclear power. A recent Hungarian publication stresses that "in the philosophy of socialism, environmental detriments may present no limitations to the welfare of society. The growing demands of society must be satisfied, since failing to do so would contravene the basic principles of socialism"'.

So far, only the dissident "Document 22 " of the Charter-77 movement has dared to question the validity of the nuclear solution. By 1990, according to the latest agreement, the nuclear generating capacity of Comecon will have been raised from the present $15-18$ million $\mathrm{kW}$ to 150 million $\mathrm{kW}, 37$ million $\mathrm{kW}$ of which will be sited outside the Soviet Union.

Meanwhile, in spite of the agreed integration programme, the search for home-based fuel sources continues throughout the non-Soviet members of the bloc. Poland has a long-standing programme of coal mine modernisation, including a sophisticated research programme into the causes of mine-gas explosions. A country-wide geological survey for oil and gas resources has produced an impressive set of maps of the various strata, and is now proceeding to the field-work stage. No detailed interim results are available, although one geologist connected with the survey told Nature, last autumn that there were "positive indications". The survey is being continued offshore by an international consortium of Poland, East Germany and the Soviet Union.

Romania, too, is looking offshore. The new draft programme for research and development to be submitted to the forthcoming congress of the Romanian Communist Party stresses the need for offshore exploration and exploitation. Not only will this include mineral wealth, but the possibility of building a pilot wavepowered generating station is also under consideration. Full use of the hydroelectric potential of the Danube is a target for 1990 , lignite and shale mining will be intensified, and a number of more exotic schemes "biogas", the extraction of hydrogen from water, and the use of geothermal energy are to be given serious consideration. By $1990 \mathrm{it}$ is intended that the country should be self-supporting in energy, while the average energy consumed per 1000 lei of industrial output is intended to fall by at least $40 \%$.

Czechoslovakia is looking closely at the home: modern flats, said the Director of the State Power Directorate recently, consume about $50 \%$ more heat than the norm, due to poor construction and installation. Yugoslavia (not a member of Comecon but closely linked with the bloc) has already decided not to build any further oil-burning power stations and to upgrade its neglected coal and lignite resources. Finland, likewise partially dependent on Soviet oil, is seriously considering the energy potentialities of scrub timber grown on marginal land. Hungary is showing a renewed interest in coal, and the latest updating of the UKHungarian Joint Commission on Technological Co-operation agreed last 
month includes a new cooperation project on coal technology. Bulgaria, while so far urging no major changes, is cautiously contributing to the energy debate by publishing statistics of $\mathrm{kW}-\mathrm{h}$ of lighting saved this year by "summer time".
Meanwhile, East Germany, although claiming that, in spite of the harsh winter conditions, planned production of electric power was "achieved as a whole after the first six months", did not allow the temporary setback to the economy to be entirely attributed to meteorological conditions. In June, a result of "shortcomings in management, especially in the ministerial sector for coal and power", Klaus Seibold, the Minister of Energy, was dismissed from office.

\section{Spanish scientists have to fight for survival}

Research in Spain is suffering from a lack of direction and funds. M Vicente, a Spanish biologist, reports on a recent meeting of scientists to discuss their plight and Emilio Munoz (below) reports on one ray of hope - the setting up of a new research ministry.

Uncertainty of direction, lack of promotion opportunities and no guarantee of long-term finance: these are the crucial problems that bedevil scientific research in Spain. They were given a public airing last month when biology and biomedical researchers met under the auspices of the CSIC (Consejo Superior de Investigaciones Cientificas). The scientists' intention was to test the reaction of the newly-created Ministry of Universities and Research (see below) to their complaints, and what emerged from the researchers amounted to a cry for survival.

The meeting had no difficulty agreeing that research policies were needed related to Spain's particular requirements. But they could not decide whether this was best approached through basic or applied research. One speaker said biology in Spain had concentrated on basic research for the past 15 years and all applied approaches had been treated as secondary. It was not surprising, he added, that there were no links between society and research and that, as a result, society was indifferent to the present scientific crisis. Other speakers defended basic research and argued that they were doing enough for society by teaching young scientists in the universities.

The second major theme of the meeting was that the country's scientific researchers were not only too few in number but also too old. The average age of Spain's scientific community was said to be around 48 and this restricted the job opportunities for young scientists. The number of young PhDs nearly doubled every four years but only one in five had a job related to his specialisation. Several causes were given for this situation, all with the same roots: the absence of long-term planning and the lack of interest in research.

Spain's scientific development during the 1960s happened at the wrong time and went in the wrong direction. The economy caught up with other developed countries, but largely because of imported foreign technology. A 10\%-a-year increase in public sector research staff was intended to accompany economic growth but never came into effect. Researchers in the private sector are even fewer and their work is limited to quality control. All these problems have now been aggravated by economic difficulties, so that Spanish research is coming of age at the worst possible time.

For scientists, the finance situation could be the most worrying of all. Because of its lack of social impact, research is not in the official list of priorities. Half way through the present year, research groups are spending the money assigned to them last year. No official programme of grants has been issued yet for next year. Unless urgent measures are taken, and experience of Spanish bureaucracy makes it unlikely that they will be, most scientists will have to stop their work early in 1980 . Even strong groups, such as those in the Molecular Biology Centre in Madrid.

A secret three-year government plan to finance research was drafted a year ago. Its text is not known, raising suspicions among scientists that it will channel money to the increasingly overcrowded universities in which research has been so difficult that it tends to be the activity of a few dilettantes. They are afraid that a decision to transfer them to academic jobs will irreversibly damage their research activities.

\section{Will the new research ministry fill the vacuum?}

SPAIN has established a Ministry of Universities and Research - a move which has been welcomed by the scientific community. Scientists have felt that the lack of an effective government science policy has been paralysing efforts to build a new structure for research in Sparn around the re-constituted Cosejo Superior de Investigaciones Cientificas (CSIC), and they hope the new ministry will fill the vacuum.

The Ministry of Universities and Research has been created by splitting the functions of the former Ministry of Education and Science, in which science had become submerged in the complicated problems of education. However, there are still fears that hopes for specific research proposals may again be disappointed. The government has not yet presented its research programme, so the reasons for the creation of the new ministry are unclear. And there is still a lack of communication between the scientific community and society. No national debate has taken place in parliament on this subject, although various sectors in the country have been demanding such a debate since 1977.

The need for a new ministry was established more clearly when the new statute of the CSIC was first put into practice. It was published in January 1978 and came into force the following June. It included a new system of government for the CSIC with the participation of collegiate bodies as advisory organs, and responsibility for the economic and scientific fields through the Scientific Council and Economic Council. This made real change in the CSIC a possibility. As with all the Spanish organisations during the time of the autocratic regime, CSIC had been conducted without any clear intent. However, the councils suffered many difficulties during their first months, due to a lack of scientific policy. The absence of any sign of a specific scientific policy has prevented a rational reorganisation of CSIC.

The reorganisation attempted by the CSIC so far has been mainly bureaucratic and administrative and is thus running the risk of becoming neither lively, dynamic nor relevant. However the Scientific
Council of CSIC has made imaginative efforts to amend its organisation. A document on the general trends of scientific policy in CSIC has been elaborated, which considers as fundamental that the activity of CSIC be adjusted to the needs of Spanish society and to the manpower and material resources of CSIC itself. The budget for 1979 allows 100 pta. (less than US \$2) per day per research worker for expenses of nonrecoverable material and this represents a significant improvement over 1978 !

Within the limited possibilities offered, CSIC has strived to overcome one of its main criticisms - its isolation from other research institutions. It is stressing agreements with universities and research institutions with the ultimate goal of resolving the existing academic power struggles. The Scientific Council of CSIC is trying to cooperate with the new Ministry of Universities and Research and recently asked for an interview with the minister with the aim of establishing contacts. 